\title{
Data-mining for Fault-Zone Detection of Distance Relay in FACTS-Based Transmission
}

\author{
Nima Salek Gilani \\ Department of Electrical \\ Engineering \\ K.N.Toosi University of \\ Technology \\ Tehran, Iran \\ Nima.salek@email.kntu.ac.ir
}

\author{
Mohammad Tavakoli Bina \\ Department of Electrical \\ Engineering \\ K.N.Toosi University of \\ Technology \\ Tehran, Iran \\ Tavakoli@eetd.kntu.ac.ir
}

\author{
Fatemeh Rahmani \\ Department of Electrical \\ Engineering \\ Lamar University \\ Beaumont, TX, USA \\ frahmani@lamar.edu
}

\author{
Mahmood Hosseini Imani \\ Department of Energy \\ DENERG \\ Politecnico di Torino \\ Turin, Italy \\ mahmood.hosseiniimani@polito.it
}

\begin{abstract}
In this study, the problem of fault zone detection of distance relaying in FACTS-based transmission lines is analyzed. Existence of FACTS devices on the transmission line, when they are included in the fault zone, from the distance relay point of view, causes different problems in determining the exact location of the fault by changing the impedance seen by the relay. The extent of these changes depends on the parameters that have been set in FACTS devices. To solve the problem associated with these compensators, two instruments for separation and analysis of three line currents, from the relay point of view at fault instance, have been utilized. The wavelet transform was used to separate the high-frequency components of the three line currents, and the support vector machine (using methods for multi-class usage) was used for classification of fault location into three protection regions of distance relay. Besides, to investigate the effects of TCSC location on fault zone detection of distance relay, two places, one in fifty percent of line length and the other in seventyfive percent of line length, have been considered as two scenarios for confirmation of the proposed method. Simulations indicate that this method is effective in the protection of FACTS-based transmission lines.
\end{abstract}

Keywords- Data-mining, Distance relay, FACTS, SVM

\section{INTRODUCTION}

Increasing demand, caused by the development of cities and growing population, draws more attention on power transmission limits. Power Electronics helps to solve the problem by introducing flexible ac transmission system (FACTS) devices. The general advantages of FACTS devices are well known. However, FACTS devices can lead to severe problems in determining the exact location of the fault when they are included in the fault zone. Distance relay's function is based on measured impedance by which they calculate the fault location. Installed FACTS devices on the transmission line change the impedance measured by distance relay, which consequently leads to wrong fault zone detection. The amount of deviation in the impedance depends on the parameters settings of the FACTS device.

In recent years, researchers have become increasingly interested in solving this issue. For modeling series capacitor in the fault period, most of the papers used the model presented by Goldsworthy [1]. In [2], a solution based on time equations of network with consideration of an extensive model of a transmission line is presented. In this solution, zone and location of the fault, independent of the fault resistance, have been estimated using two subroutines. Some papers developed their methods using measurements from principle components of the main frequency. Saha et al. in [3] developed a method based on components of main frequency on one side of the transmission line using the Goldsworthy model.

In [4], an algorithm based on forward and backward waves is presented to protect series compensated transmission lines; although only one phase to ground fault has been analyzed in this paper.

Data have been presented in the literature [5-7] which suggest methods based on neural networks. It has been suggested to use RBFN as a radial neural network to classify fault type and fault location [7]. Reference [6] trains two different types of neural networks to identify fault type and location. Also, [5] uses the EDBD algorithm to calculate the fault location. Neural networks have limitations, including their need for a massive amount of neurons to model network structure. Therefore, numerous data from the electrical network is needed, and also much time to train the network. Nevertheless, these papers used a limited number of data to test their methods.

Girgis et al. in [8] proposed a method based on Kalman filter [9] which estimate the state of a dynamic system from a series of measurements containing errors. In [10], a method using wavelet transform is suggested. In both [8] and [10], limited cases have been used to assess the effectiveness of the proposed methods. Furthermore, in [10] high sampling frequency of 200 $\mathrm{KHz}$ is used, which seems to be difficult in practical implementation.

In [11], a data mining method is used for three purposes. Support vector machine (SVM) has become a popular tool in the power grid [12]. In this paper, three separate SVM is trained to determine fault location, presence or absence of fault and whether the fault includes the ground or not. This reference uses samples of firing angle and current, starting from the fault instance till half cycle after it. Considering $400 \mathrm{kV}$ and $50 \mathrm{~Hz}$ case study and sampling frequency of $1 \mathrm{KHz}$ in this paper, ten samples of current from each phase is analyzed. In this paper, fault location is confined to before and after the compensator, and its effectiveness is studied only in 200 cases. 
In [13], a two stage method is proposed to identify the fault location. In this paper, samples of three line currents for one cycle after the fault instance is used to train SVM. Considering $400 \mathrm{kV}$ and $50 \mathrm{~Hz}$ case study and sampling frequency of $1 \mathrm{KHz}$ in this paper, 80 samples of current from each phase is analyzed. In the first stage, high frequencies of three line currents are separated using wavelet transform; then in the second stage, these separated signals are given to SVM to classify the fault location to before and after the compensator. The problem is that the model used for simulation of the transmission line is not proper to study non-base frequencies while this paper used high frequencies to separate the fault locations. This method, considering using SVM, can only separate the fault location to before and after the compensator. Taking into account $400 \mathrm{kV}$ and $50 \mathrm{~Hz}$ case study and sampling frequency of $1 \mathrm{KHz}$ in this paper, 60 samples are analyzed.

Researchers in [14] proposed the random forest method [1518] to identify the fault location. This data mining method is founded based on the decision tree (DT) method. In this method, several independent unpruned decision trees are produced using different subsets of the data. Each tree has one vote, and the most vote determines the result. Samples of current and voltage in half cycle after the fault instance are utilized for analysis. Seventy percent of the samples are used for the training process of random forest, and the remaining thirty percent is used for the testing process. Considering a large amount of training data, good results have been achieved. Similarly, in this paper, the fault location is limited to before and after the compensator.

The object of this research is to improve distance protection performance, using data mining methods while considering FACTS-based transmission lines. Earlier works using artificial neural network suffer from limitations on high number of neurons. These limitations can be overcome by using more efficient tools like support vector machines. Furthermore, a more precise simulation of the transmission line is conducted here using PSCAD/EMTDC software, as well as separating the fault areas into three zones according to distance relay settings. Besides, to investigate the effects of TCSC location on fault zone detection of distance relay, two places --one in fifty percent of line length and the other in seventy five percent of line length- have been considered as two scenarios for confirmation of the proposed method. The simulations show a $94.2 \%$ of success rate in scenario one and $86.7 \%$ in the other, which are high success rates, which indicate that placing TCSC in fifty percent of line length leads to a higher prediction accuracy. Moreover, these success rates are achieved using only $15.2 \%$ of total data as the training set, which shows the high capability of proposed method.

\section{PROPOSED METHOD}

In this study, PSCAD software is used for simulation. Three line currents are recorded after creating a variety of fault conditions on the simulated transmission line. These outputs from PSCAD are used as inputs to wavelet transform in order to extract high frequencies (between 1000 to $2000 \mathrm{~Hz}$ ). It is reported in [19] and [20] that the most proper wavelet in studying faults in power system is Daubechies (db) wavelets. In [13], it was reported that from different types of $\mathrm{db}$ mother wavelets, db2 gives the best results in the detection of fault location, in the presence of series capacitor in a transmission line. It was also reported that frequencies between 1000 to 2000 $\mathrm{Hz}$ are suitable for best fault zone classification. Therefore, considering a sampling frequency of $4 \mathrm{KHz}$ in PSCAD in this study, single-level discrete wavelet transform with $\mathrm{db} 2$ mother wavelet is carried out to obtain high frequency samples. After that, wavelet transform's outputs are used as inputs to SVM to create a hyper plane to separate fault zones.

\section{CASE STUDIES}

\section{A. Simulation of case studies in PSCAD}

For TCSC simulation in PSCAD, reference model in [13] is used. This model is shown in Fig. 1. The capacitance of SC capacitor changes in proportion with the firing angle.

The feasibility of the proposed method is evaluated on a 400 $\mathrm{kV} 50 \mathrm{~Hz}$ power system. Both sides of this network are two sources that represent two areas which are connected together. The source data at both sides of the transmission line is shown in Table I. Frequency-dependent (phase) model is used for detailed simulation of transmission line. Transmission line data is achieved from a real $400 \mathrm{kV}$ single-circuit transmission line with a length of $250 \mathrm{~km}$. this data is presented in Table II.

Following this line of 250 kilometers, a line with a length of $100 \mathrm{~km}$ and then a line with length of $50 \mathrm{~km}$ with the same profile was considered. To evaluate the impact of TCSC location on the issue of protection, this element was placed in two locations, first in the middle of the line $1(125 \mathrm{~km}$ of line 1$)$ and second, in Seventy-five percent of the line $1(187.5 \mathrm{~km}$ of line 1 ), which in continuation of this paper for the convenience of readers will be referred to as scenario 1 and scenario 2, respectively. Three protection zones have been defined for distance relay, first till 80 percent of the first line, second till 50 percent of the second line and third till 25 percent of the third line.

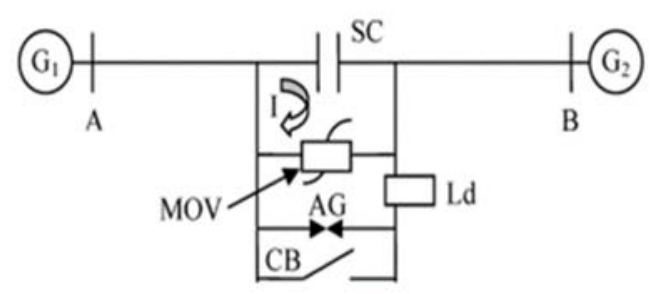

Fig 1. TCSC simulation model [13]

TABLE I. SOURCE DATA AT BOTH ENDS

\begin{tabular}{|c|c|}
\hline Parameters & Value \\
\hline Source Voltage & $400 \mathrm{kV}$ \\
\hline Frequency & $50 \mathrm{~Hz}$ \\
\hline Positive sequence impedance & $1.31+\mathrm{j} 15 \Omega$ \\
\hline Zero sequence impedance & $2.33+j 26.6 \Omega$ \\
\hline
\end{tabular}


TABLE II . TRANSMISSION LINE DATA

\begin{tabular}{|c|c|c|c|}
\hline Data type & value & Data type & value \\
\hline $\begin{array}{c}\text { Arrangement of } \\
\text { wires }\end{array}$ & Horizontal & Vertical distance of conductors & $15.45 \mathrm{~m}$ \\
\hline Line length & $250 \mathrm{~km}$ & SAG for all conductors & $14 \mathrm{~m}$ \\
\hline Number of bundle & 2 & Number of ground wires & 2 \\
\hline Bundle spacing & $45 \mathrm{~cm}$ & $\begin{array}{c}\text { Height of ground wires above the } \\
\text { lowest conductor }\end{array}$ & $9.36 \mathrm{~m}$ \\
\hline $\begin{array}{c}\text { Conductor DC } \\
\text { resistance }\end{array}$ & $0.0553 \mathrm{ohm} / \mathrm{km}$ & Ground wire DC resistance & $1.463 \mathrm{ohm} / \mathrm{km}$ \\
\hline Conductor GMR & $1.2161 \mathrm{~cm}$ & Ground wire radius & $0.2445 \mathrm{~cm}$ \\
\hline Height of conductors & $41.46 \mathrm{~m}$ & Spacing between ground wires & $18.70 \mathrm{~m}$ \\
\hline
\end{tabular}

In scenario one which TCSC is placed in the middle of the first line, four fault locations are assumed: in $50 \mathrm{~km}$ (first zone, before TCSC), in $150 \mathrm{~km}$ (first zone, after TCSC), in $250 \mathrm{~km}$ (second zone), in $325 \mathrm{~km}$ (third zone). In scenario 2, three fault locations are assumed: in $100 \mathrm{~km}$ (first zone), in $250 \mathrm{~km}$ (second zone), in $325 \mathrm{~km}$ (third zone).

In order to evaluate the feasibility of proposed method under various system condition, different kinds of fault type, fault resistance, fault inception angle (FIA), load angle $(\delta)$, generator impedance, compensation percentage and fault location, which include 28800 cases for scenario 1 and 21600 cases for scenario 2 , have been analyzed utilizing multiple run in PSCAD. Table III shows considered cases. $25 \%, 50 \%$, and $75 \%$ are chosen TCSC compensation percentages for $250 \mathrm{~km}$ transmission line, their equivalent value for SC capacitor is $120.45,60.225$ and $40.15 \mu \mathrm{f}$ respectively.

Randomly chosen cases for the training process of SVM are 3600 cases for scenario 1 and 2700 cases for scenario 2 . These cases are only $12.5 \%$ of the total data set and are shown in Table IV. The Gaussian RBF kernel has been used for training and testing process in SVM.

\section{B. Classification with One-Against-All method (OAA)}

.There are various ways to use SVM to classify data into more than two classes. In OAA assuming $\mathrm{k}$ classes, $\mathrm{k}$ SVM is trained for each class with the samples of that class as positive samples and all other samples as negatives.

\section{1) Analysis of scenario 1}

Getting a proper output from SVM can be achieved through metaheuristic algorithms or trial and error learning [13]. In order to utilize trial and error learning different values for regularization parameter (C) and gamma (g) (RBF kernel parameter) should be evaluated on the classification of training data in order to choose the best ones, then the result is used to classify the test data. For the range of these parameters, results in reference [13] was a great help. The best result is achieved in 21096 and 14.5 for $\mathrm{C}$ and g, respectively. With these values, $83.7 \%$ of success is achieved in fault zone detection.

\section{2) Analysis of scenario 2}

In result analysis of scenario two, it could be seen that the most number of correct fault zone detection was reached with

TABLE III. CONSIDERED CASES FOR SYSTEM ANALYSIS

\begin{tabular}{|c|c|c|c|c|c|c|c|c|c|c|}
\hline \multirow[b]{2}{*}{$\begin{array}{l}\text { Case } \\
\text { number }\end{array}$} & \multirow[b]{2}{*}{$\begin{array}{l}\text { Number } \\
\text { of fault } \\
\text { cases for } \\
\text { scenario } 1\end{array}$} & \multirow{2}{*}{$\begin{array}{l}\text { Number of } \\
\text { fault cases } \\
\text { for } \\
\text { scenario } 2\end{array}$} & \multicolumn{8}{|c|}{ Parameters } \\
\hline & & & $\% \mathrm{Z}_{\mathrm{G} 1}$ & $\% \mathrm{Z}_{\mathrm{G} 2}$ & $\% X c$ & $R_{f}$ & FIA & $\delta$ & $\begin{array}{l}\text { Fault } \\
\text { types }\end{array}$ & $\begin{array}{l}\text { Fault } \\
\text { locations }\end{array}$ \\
\hline 1 & 5760 & 4320 & 100 & 100 & \multirow{5}{*}{$\begin{array}{c}25,50 \\
\& \\
75\end{array}$} & \multirow{5}{*}{$\begin{array}{c}0,5 \\
\& \\
25,50\end{array}$} & \multirow{5}{*}{$\begin{array}{c}0,45 \\
\quad \& \\
81,117\end{array}$} & \multirow{5}{*}{$\begin{array}{c}10,20 \\
\& \\
30\end{array}$} & \multirow{5}{*}{10} & \multirow{5}{*}{$\begin{array}{c}4 \text { and } 3 \\
\text { location for } \\
\text { scenario } 1 \\
\text { and } \\
\text { scenario } 2 \\
\text { respectively }\end{array}$} \\
\hline 2 & 5760 & 4320 & 100 & 75 & & & & & & \\
\hline 3 & 5760 & 4320 & 100 & 125 & & & & & & \\
\hline 4 & 5760 & 4320 & 75 & 100 & & & & & & \\
\hline 5 & 5760 & 4320 & 125 & 100 & & & & & & \\
\hline \multicolumn{11}{|c|}{ total number of cases in scenario $1=5 * 5760=28800$} \\
\hline & & & -1 & 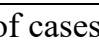 & & & $=21600$ & & & \\
\hline
\end{tabular}


TABLE IV. CHOSEN CASES FOR TRAINING PROCESS OF SVM

\begin{tabular}{|c|c|c|c|c|c|c|c|c|c|c|}
\hline \multirow[b]{2}{*}{$\begin{array}{c}\text { Case } \\
\text { number }\end{array}$} & \multirow{2}{*}{$\begin{array}{l}\text { Number } \\
\text { of fault } \\
\text { cases for } \\
\text { scenario } 1\end{array}$} & \multirow{2}{*}{$\begin{array}{l}\text { Number of } \\
\text { fault cases } \\
\text { for } \\
\text { scenario } 2\end{array}$} & \multicolumn{8}{|c|}{ Parameters } \\
\hline & & & $\% \mathrm{Z}_{\mathrm{G} 1}$ & $\% \mathrm{Z}_{\mathrm{G} 2}$ & $\% \mathrm{X}_{\mathrm{c}}$ & $\mathrm{R}_{\mathrm{f}}$ & FIA & $\delta$ & $\begin{array}{l}\text { Fault } \\
\text { types }\end{array}$ & $\begin{array}{c}\text { Fault } \\
\text { locations }\end{array}$ \\
\hline 1 & 720 & 540 & 100 & 100 & 50 & \multirow{5}{*}{$\begin{array}{l}0,5 \\
\& \\
50\end{array}$} & \multirow{5}{*}{$\begin{array}{c}0,45 \\
\& \\
117\end{array}$} & \multirow{5}{*}{$\begin{array}{l}10 \\
\& \\
30\end{array}$} & \multirow{5}{*}{10} & \multirow{5}{*}{$\begin{array}{c}4 \text { and } 3 \\
\text { location for } \\
\text { scenario } 1 \\
\text { and } \\
\text { scenario } 2 \\
\text { respectively }\end{array}$} \\
\hline 2 & 720 & 540 & 100 & 75 & 50 & & & & & \\
\hline 3 & 720 & 540 & 100 & 125 & 50 & & & & & \\
\hline 4 & 720 & 540 & 75 & 100 & 50 & & & & & \\
\hline 5 & 720 & 540 & 125 & 100 & 50 & & & & & \\
\hline \multicolumn{11}{|c|}{ total number of cases in scenario $1=5 * 720=3600$} \\
\hline \multicolumn{11}{|c|}{ total number of cases in scenario $2=5 * 540=2700$} \\
\hline
\end{tabular}

$\mathrm{C}=1080000$ and $\mathrm{g}=38.4$. The success rate was $69.7 \%$, which was less than scenario one. In section IV causes of this lower success rate will be discussed.

\section{Classification with One-Against-One method (OAO)}

For this method, a table should be established, and each SVM should cast its vote on a class between two classes. The class that achieves the highest number of votes is chosen by the combined classifiers. Possible scenarios are shown in Table V.

\section{1) Analysis of scenario 1}

The maximum number of correct detection of fault zone using OAO in scenario 1 was 20629 cases which happened in $\mathrm{C}=10000$ and $\mathrm{g}=13.1$. This number is equivalent to $81.8 \%$ of success.

Following up on OAO method, with analysis of results, one can decide for cases that the table cannot vote for their class. After checking the results, Table V was replaced with Table VI.

The maximum number of correct detections of fault zone using Table VI was 21239, which happened in $\mathrm{C}=10$ and $\mathrm{g}=10.4$. As expected, the success rate increased to $84.2 \%$.

\section{2) Analysis of scenario 2}

The maximum number of correct detection of fault zone using OAO in scenario 2 was 11802 cases which happened in $\mathrm{C}=10$ and $\mathrm{g}=20$. This number is equivalent to $\% 62.2$ of success. After replacing Table $\mathrm{V}$ by Table VI number of correct cases increased to 123399 in $\mathrm{C}=10$ and $\mathrm{g}=21.3$, which is equivalent to $65.6 \%$ of success.

\section{Classification with OAA method in the modified training set}

As can be seen, a substantial percentage of success was not achieved for scenario 1 and 2 with both methods. One of the effective parameters to achieve a good result in classification is having a proper and right amount of training data set. One cannot expect an algorithm to predict properly in unseen areas. It is usual to put $70 \%$ of the data set into the training set and $30 \%$ to the test set. Until now, only $12.5 \%$ of the data set was used in the training set. Cases, which their fault zone was identified incorrectly, were analyzed. A high proportion of wrong predictions happened in data with load angles $(\delta)$ equal to 20 , which was not included in the training data set. Therefore, random data sets with load angles $(\delta)$ equal to 20 were added to the training set. Table VII and Table VIII Shows the added data for scenario 1 and scenario 2, respectively. Consider that now $15.3 \%$ of total data is used as the training data set.

\section{1) Analysis of scenario 1}

The maximum number of correct detection of fault zone using OAA in the modified training set was 22993 cases which happened in $\mathrm{C}=10$ and $\mathrm{g}=8.3$. Modified training set increased the success rate from $83.7 \%$ to $94.2 \%$.

\section{2) Analysis of scenario 2}

The maximum number of correct detection of fault zone using OAA in the modified training set was 15880 cases which happened in $\mathrm{C}=10$ and $\mathrm{g}=14.5$. Modified training set increased the success rate from $69.7 \%$ to $86.2 \%$.

TABLE V. POSSIBLE SCENARIOS IN VOTING

\begin{tabular}{|c|c|c|c|c|c|c|c|c|}
\hline Groups & \multicolumn{7}{|c|}{ Possible conditions } \\
\hline 1,2 & 1 & 1 & 1 & 1 & 0 & 0 & 0 & 0 \\
\hline 1,3 & 1 & 1 & 0 & 0 & 1 & 1 & 0 & 0 \\
\hline 2,3 & 0 & 1 & 0 & 1 & 0 & 1 & 1 & 0 \\
\hline result & 1 & 1 & 3 & 0 & 0 & 2 & 2 & 3 \\
\hline
\end{tabular}

TABLE VI. MODIFIED SCENARIOS IN VOTING

\begin{tabular}{|c|c|c|c|c|c|c|c|c|}
\hline Groups & \multicolumn{7}{|c|}{ Possible conditions } \\
\hline 1,2 & 1 & 1 & 1 & 1 & 0 & 0 & 0 & 0 \\
\hline 1,3 & 1 & 1 & 0 & 0 & 1 & 1 & 0 & 0 \\
\hline 2,3 & 0 & 1 & 0 & 1 & 0 & 1 & 1 & 0 \\
\hline result & 1 & 1 & 3 & 3 & 2 & 2 & 2 & 3 \\
\hline
\end{tabular}




\section{DISCUSSION ON THE RESULTS}

TABLE VII. ADDED DATA TO TRAINING SET IN SCENARIO 1

\begin{tabular}{|c|c|c|c|c|c|c|c|}
\hline \multirow{2}{*}{$\begin{array}{c}\text { Case } \\
\text { number }\end{array}$} & \multirow{2}{*}{$\begin{array}{c}\text { Number } \\
\text { of fault } \\
\text { cases }\end{array}$} & \multicolumn{6}{|c|}{ Parameters } \\
\hline & & $\% \mathrm{Z}_{\mathrm{G} 1}$ & $\% \mathrm{Z}_{\mathrm{G} 2}$ & $\% \mathrm{X}_{\mathrm{C}}$ & $\mathrm{R}_{\mathrm{f}}$ & FIA & $\delta$ \\
\hline 1 & 160 & 100 & 100 & \multirow{5}{*}{$\begin{array}{l}25 \\
\& \\
50\end{array}$} & \multirow{5}{*}{50} & \multirow{5}{*}{$\begin{array}{c}81 \\
\& \\
117\end{array}$} & \multirow{5}{*}{20} \\
\hline 2 & 160 & 100 & 75 & & & & \\
\hline 3 & 160 & 100 & 125 & & & & \\
\hline 4 & 160 & 75 & 100 & & & & \\
\hline 5 & 160 & 125 & 100 & & & & \\
\hline \multicolumn{8}{|c|}{ Total number $=5 * 160=800$} \\
\hline
\end{tabular}

TABLE VIII. ADDED DATA TO TRAINING SET IN SCENARIO 2

\begin{tabular}{|c|c|c|c|c|c|c|c|}
\hline \multirow{2}{*}{$\begin{array}{c}\text { Case } \\
\text { number }\end{array}$} & \multirow{2}{*}{$\begin{array}{l}\text { Number } \\
\text { of fault } \\
\text { cases }\end{array}$} & \multicolumn{6}{|c|}{ Parameters } \\
\hline & & $\% \mathrm{Z}_{\mathrm{G} 1}$ & $\% \mathrm{Z}_{\mathrm{G} 2}$ & $\% \mathrm{X}_{\mathrm{C}}$ & $\mathrm{R}_{\mathrm{f}}$ & FIA & $\delta$ \\
\hline 1 & 120 & 100 & 100 & \multirow{5}{*}{$\begin{array}{l}25 \\
\& \\
50\end{array}$} & \multirow{5}{*}{$\begin{array}{l}0 \\
\& \\
50\end{array}$} & \multirow{5}{*}{81} & \multirow{5}{*}{20} \\
\hline 2 & 120 & 100 & 75 & & & & \\
\hline 3 & 120 & 100 & 125 & & & & \\
\hline 4 & 120 & 75 & 100 & & & & \\
\hline 5 & 120 & 125 & 100 & & & & \\
\hline \multicolumn{8}{|c|}{ Total number $=5 * 120=600$} \\
\hline
\end{tabular}

TABLE IX. MODIFIED SCENARIOS IN VOTING FOR SECTION E

\begin{tabular}{|c|c|c|c|c|c|c|c|c|}
\hline Groups & \multicolumn{7}{|c|}{ Possible conditions } \\
\hline 1,2 & 1 & 1 & 1 & 1 & 0 & 0 & 0 & 0 \\
\hline 1,3 & 1 & 1 & 0 & 0 & 1 & 1 & 0 & 0 \\
\hline 2,3 & 0 & 1 & 0 & 1 & 0 & 1 & 1 & 0 \\
\hline result & 1 & 1 & 3 & 2 & 3 & 2 & 2 & 3 \\
\hline
\end{tabular}

\section{E. Classification with $O A O$ method in the modified training set}

1) Analysis of scenario 1

In this case, the best result is achieved in $\mathrm{C}=10$ and $\mathrm{g}=12.1$. With these values, the success rate is increased to $86.7 \%$. After analyzing the results, Table V was replaced with Table IX as the reference voting table. The results showed $91.6 \%$ success rate in $\mathrm{C}=10$ and $\mathrm{g}=12.1$.

\section{1) Analysis of scenario 2}

The results showed $76.1 \%$ success rate in $\mathrm{C}=100000$ and $\mathrm{g}=15.3$, which is equivalent to 13926 correct fault zone detections. After analyzing the results, Table $\mathrm{V}$ was replaced with Table IX as the reference voting table. The results showed $78.2 \%$ success rate in $\mathrm{C}=100000$ and $\mathrm{g}=15.4$, which is equivalent to 14318 correct fault zone detections.
According to the results, the highest success rate is achieved in scenario 1 (installing TCSC in the middle of the first line). This success rate $(94.2 \%)$ was reached with OAA method on the modified training set. In scenario two, the highest success rate was $86.7 \%$, which was also reached with OAA method on the modified training set. Thus, the prominent role of selecting a proper training data set had become evident. To investigate why scenario 2 had less success rate than scenario 1, cases with the wrong detection of the fault zone in both scenarios were analyzed in Table X and Table XI. By comparing these two tables, it can be concluded that an increase in wrong zone detections happened in zone 2 and 3, whereas in zone 1 it almost remained constant. In other words, SVM made more mistakes because pushing the TCSC forward increased its area of influence.

\section{CONCLUSIOIN}

In this paper, a new method for fault zone detection of distance relay in FACTS-based transmission lines has been proposed. For investigating the effects of TCSC location on fault zone detection of distance relay, two places, one in fifty percent of line length and the other in seventy-five percent of line length, have been considered as two scenarios. In total, four cases have been considered for each scenario. For scenario 1, with OAA method, $83.7 \%$ of success, and with OAO method, $84.4 \%$ of success have been achieved. After analyzing the result and increasing the training set, with OAA method, $94.2 \%$ of success and with OAO method, $91.6 \%$ of success have been achieved. For scenario 2, with OAA method, $69.7 \%$ of success, and with OAO method, $65.6 \%$ of success have been achieved. After analyzing the result and increasing the training set, with OAA

TABLE X. NUMBER OF WRONG PREDICTIONS IN SCENARIO 1

\begin{tabular}{|c|c|c|c|c|}
\hline Predicted zone & 1 & 2 & 3 & $\begin{array}{c}\text { Total number } \\
\text { of wrong } \\
\text { prediction in } \\
\text { each zone }\end{array}$ \\
\hline 1 & & 99 & 211 & 310 \\
\hline 2 & 249 & & 512 & 761 \\
\hline 3 & 193 & 143 & & 336 \\
\hline
\end{tabular}

TABLE XI. NUMBER OF WRONG PREDICTIONS IN SCENARIO 2

\begin{tabular}{|c|c|c|c|c|}
\hline Predicted zone & 1 & 2 & 3 & $\begin{array}{c}\text { Total number } \\
\text { of wrong } \\
\text { prediction in } \\
\text { each zone }\end{array}$ \\
\hline 1 & & 91 & 237 & 328 \\
\hline 2 & 829 & & 613 & 1442 \\
\hline 3 & 381 & 283 & & 644 \\
\hline
\end{tabular}


method, $86.7 \%$ of success and with OAO method, $78.2 \%$ of success have been achieved. Results showed that in solving this type of problem, ultimately, the OAA method has a comparative advantage over the OAO method. With the OAA method, $94.2 \%$ and $86.7 \%$ of success have been achieved in scenario 1 and 2, respectively. It was shown that installing TCSC in the middle of the first line leads to better results by decreasing its influence on zone 2 and 3 of the distance relay. Transmission lines are vital parts of power system. Improving their protection is necessary for reliability of the network. This paper presents a novel approach to increase the reliability of the system by improving the protection of transmission lines in fault instance and minimizing the damage to other network equipment. Rapid detection and isolation of a faulty transmission line, protect the network from its possible harmful effects

\section{REFERENCES}

[1] Goldsworthy, Daniel L. "A linearized model for MOV-protected series capacitors." IEEE Transactions on Power Systems 2, no. 4 (1987): 953957.

[2] Sadeh, Javad, A. M. Ranjbar, N. Hadsaid, and R. Feuillet. "Accurate fault location algorithm for series compensated transmission lines." In 2000 IEEE Power Engineering Society Winter Meeting. Conference Proceedings (Cat. No. 00CH37077), vol. 4, pp. 2527-2532. IEEE, 2000.

[3] Saha, M. M., J. Izykowski, E. Rosolowski, and B. Kasztenny. "A new accurate fault locating algorithm for series compensated lines." IEEE Transactions on Power Delivery 14, no. 3 (1999): 789-797.

[4] Thomas, D. W. P., and C. Christopoulos. "Ultra-high speed protection of series compensated lines." IEEE Transactions on Power Delivery 7, no. 1 (1992): 139-145.

[5] Xuan, Q. Y., Y. H. Song, A. T. Johns, R. Morgan, and D. Williams. "Performance of an adaptive protection scheme for series compensated EHV transmission systems using neural networks." Electric power systems research 36, no. 1 (1996): 57-66.

[6] Song, Y. H., A. T. Johns, and Q. Y. Xuan. "Artificial neural-networkbased protection scheme for controllable series-compensated EHV transmission lines." IEE Proceedings-Generation, Transmission and Distribution 143, no. 6 (1996): 535-540.

[7] Song, Y. H., Q. Y. Xuan, and A. T. Johns. "Protection scheme for EHV transmission systems with thyristor controlled series compensation using radial basis function neural networks." Electric machines and power systems 25, no. 5 (1997): 553-565.
[8] Girgis, Adly A., A. A. Sallam, and A. Karim El-Din. "An adaptive protection scheme for advanced series compensated (ASC) transmission lines." IEEE Transactions on Power Delivery 13, no. 2 (1998): 414-420.

[9] Kalman, Rudolph Emil. "A new approach to linear filtering and prediction problems." Journal of basic Engineering 82, no. 1 (1960): 35-45.

[10] Megahed, Ashraf I., A. Monem Moussa, and A. E. Bayoumy. "Usage of wavelet transform in the protection of series-compensated transmission lines." IEEE Transactions on Power Delivery 21, no. 3 (2006): 12131221.

[11] Dash, P. K., S. R. Samantaray, and Ganapati Panda. "Fault classification and section identification of an advanced series-compensated transmission line using support vector machine." IEEE transactions on power delivery 22, no. 1 (2006): 67-73.

[12] Fattaheian-Dehkordi, Sajjad, Alireza Fereidunian, Hamid GholamiDehkordi, and Hamid Lesani. "Hour-ahead demand forecasting in smart grid using support vector regression (SVR)." International transactions on electrical energy systems 24, no. 12 (2014): 1650-1663.

[13] Parikh, Urmil B., Biswarup Das, and Rudra Prakash Maheshwari. "Combined wavelet-SVM technique for fault zone detection in a series compensated transmission line." IEEE Transactions on Power Delivery 23, no. 4 (2008): 1789-1794.

[14] Samantaray, S. R. "A data-mining model for protection of FACTS-based transmission line." IEEE Transactions on Power Delivery 28, no. 2 (2013): 612-618.

[15] Banfield, Robert E., Lawrence O. Hall, Kevin W. Bowyer, and W. Philip Kegelmeyer. "A comparison of decision tree ensemble creation techniques." IEEE transactions on pattern analysis and machine intelligence 29, no. 1 (2006): 173-180.

[16] Lepping, Joachim. "Wiley Interdisciplinary Reviews: Data Mining and Knowledge Discovery." (2018).

[17] Imani, Mahmood Hosseini, Payam Niknejad, and M. R. Barzegaran. "Implementing Time-of-Use Demand Response Program in microgrid considering energy storage unit participation and different capacities of installed wind power." Electric Power Systems Research 175 (2019): 105916.

[18] Provost, Foster, and Pedro Domingos. "Tree induction for probabilitybased ranking." Machine learning 52, no. 3 (2003): 199-215.

[19] Megahed, Ashraf I., A. Monem Moussa, and A. E. Bayoumy. "Usage of wavelet transform in the protection of series-compensated transmission lines." IEEE Transactions on Power Delivery 21, no. 3 (2006): 12131221.

[20] Zhang, Nan, and Mladen Kezunovic. "Transmission line boundary protection using wavelet transform and neural network." IEEE Transactions on Power Delivery 22, no. 2 (2007): 859-869. 